\title{
Commodity culture: tropical health and hygiene in the British Empire
}

\section{Ryan Johnson}

Wellcome Unit for the History of Medicine, University of Oxford, Oxford OX2 6PE, UK

\begin{abstract}
Before heading to a 'tropical' region of the Empire, British men and women spent considerable time and effort gathering outfit believed essential for their impending trip. Ordinary items such as soap, clothing, foodstuffs and bedding became transformed into potentially life-saving items that required the fastidious attention of any would-be traveller. Everyone from scientists and physicians to missionaries and administrators was bombarded by relentless advertising and abundant advice about the outfit needed to preserve health in a tropical climate. A closer look at this marketing exercise reveals much about the way people thought about tropical people, places, health and hygiene and how scientific and commercial influences shaped this Imperial commodity culture.
\end{abstract}

\section{The Livingstone Exhibition}

On a foggy afternoon in the centre of London, 1 January 1900, the spacious St. Martin's Town Hall in Charing Cross was overflowing with goods destined for exotic locales and designed for the preservation of white European health in tropical climates [1]. Influential empire builders, physicians, politicians, missionaries, traders, planters and countless others interested in Britain's tropical processions were also present in great supply. The somewhat narrow, but lofty hall hosted the first of two Livingstone Exhibitions, where patrons could gaze at a surprisingly vast material and commodity culture associated with health, hygiene and travel to the British tropical colonies (Figure 1). The main aim of the exhibition was to showcase the advances in maintaining health and hygiene in the notoriously deadly 'tropics'. But on a day that ushered in the twentieth century, the first Livingstone Exhibition was also a celebration of the expanding British Empire.

The organiser of the Livingstone Exhibitions, Charles Forbes Harford-Battersby, was a former Church Missionary Society (CMS) medical missionary and had travelled and worked extensively in northern Nigeria. It is here that he probably met and befriended Sir George Taubman-Goldie, founder of the National African Company, later to become the chartered Royal Niger Company and Niger Territories. With a little encouragement, Goldie had graciously agreed to act as president of the Livingstone Exhibitions.

Just hours before his presidential address at St. Martin's Hall, Goldie had signed over the rule and administration of the Niger Territories to Her Majesty's Government for the

Corresponding author: Johnson, R. (ryan.johnson@sant.ox.ac.uk)

Available online 6 May 2008 sum of $£ 865,000$. This, wrote Battersby, released him 'from the arduous post he had filled so long and so well'. That morning, as he addressed those gathered for the opening of the Livingstone Exhibition, Goldie 'referred with great satisfaction to the various steps which had been taken in recent years, to deal with the great problem of the preservation of health of Europeans in dangerous climates'. He spoke of the importance of Empire, not only for the betterment of Britain but also for the 'uncivilised' people of the world, and closed by welcoming in a diverse crowd to survey products that might save their lives in the 'dangerous' tropical world [2].

First through the doors was Her Royal Highness the Princess Christian, acting as the Exhibition's Patron, followed by the Marquis of Salisbury representing the Foreign Office, Lord George Hamilton of the India Office, Lord Lansdowne of the War Office and Mr. Joseph Chamberlain of the Colonial Office. Students and staff from the London and Liverpool schools of tropical medicine filed in, along with several prominent members of the Royal Geographical Society eager to pay tribute to their one-time president David Livingstone. The use of his name to frame the exhibition was carefully calculated. The tales of Livingstone marching confidently into Africa's steamy, plush jungles with their danger and disease continued to captivate the imagination of a public obsessed with colonial conquest and expansion.

Indeed, one of the most popular features of the exhibition was a display of items Livingstone carried on his travels, including two original maps, photographs, a sextant, boiling point thermometer, aneroid barometer, compass and 'an instrument for determining the artificial horizon' [1] (Figure 2). For Battersby, there was a 'remarkable contrast between the implements which Livingstone was compelled to use in his journeys and the perfection of the modern instruments and outfit as shown in the adjoining room', one that made the 'great advantages of the modern conveniences of travel, which were on view in the General Exhibition' all the more obvious [1]. In addition, the presentation of Livingstone's archaic and quaint tools alongside modern equipment reinforced notions of western progress, authority and an ability to control unruly spaces, while simultaneously asserting the supposed moral and racial superiority of white Europeans over local men and women in the tropical colonies [3].

The main exhibition carried just about everything needed for life in a tropical climate. There were displays of tents and camp equipment, featuring goods from the S.W. Silver \& Company and The Military Equipment Company. At one stall, patrons could take a look at a 


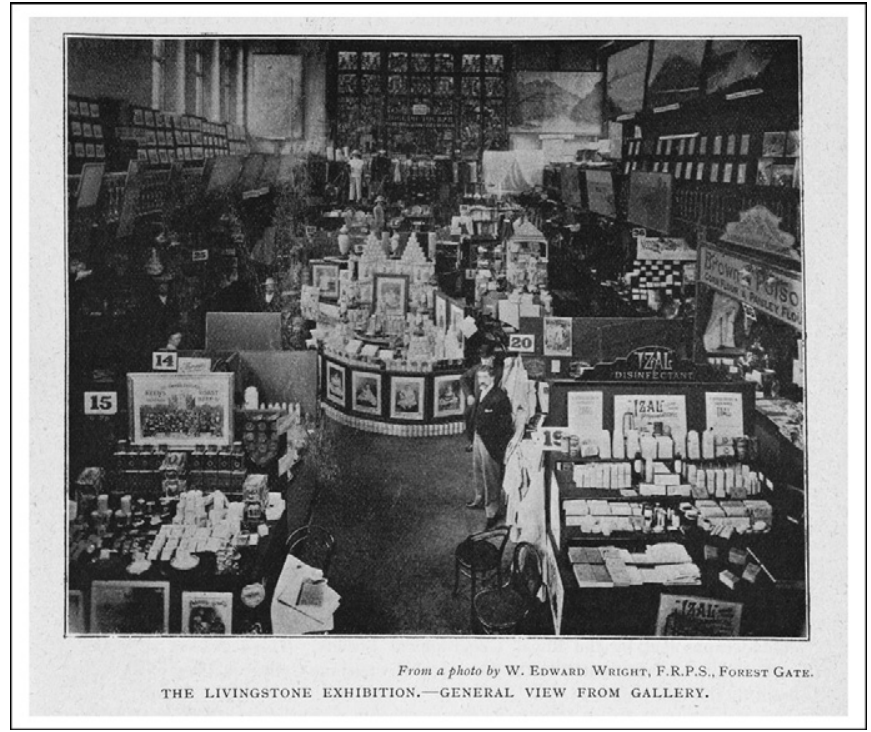

Figure 1. A view of the Livingstone Exhibition from the Gallery. Reproduced from Climate 1(4), 1900, p. 135. Wellcome Library, London.

life-like tropical scene, peering inside a tent to find a bed and bedding, mosquito net and articles of tropical clothing. The man who had assembled it, Mr. Joseph Tucker, could 'provide everything a missionary can require' noted Battersby [4]. There was also considerable space devoted to foodstuffs suitable for tropical travel, notably fresh vegetables, which were frequently in short supply in tropical climates. Merchants touting 'desiccated' vegetables stressed the light-weight and compact nature of their dried and sealed produce. Battersby wondered whether they were 'in all cases palatable', though was convinced that from the 'point of view of health there can be little question of their superiority' [4]. Bovril Limited and the Portable Food Company displayed rations, while the Anglo-Swiss Milk Company, Frame Food and Allenbury's Food presented what were considered appropriate foodstuffs for children.

There were displays dedicated to medicine. For example, scientific instrument maker Mr. James J. Hicks

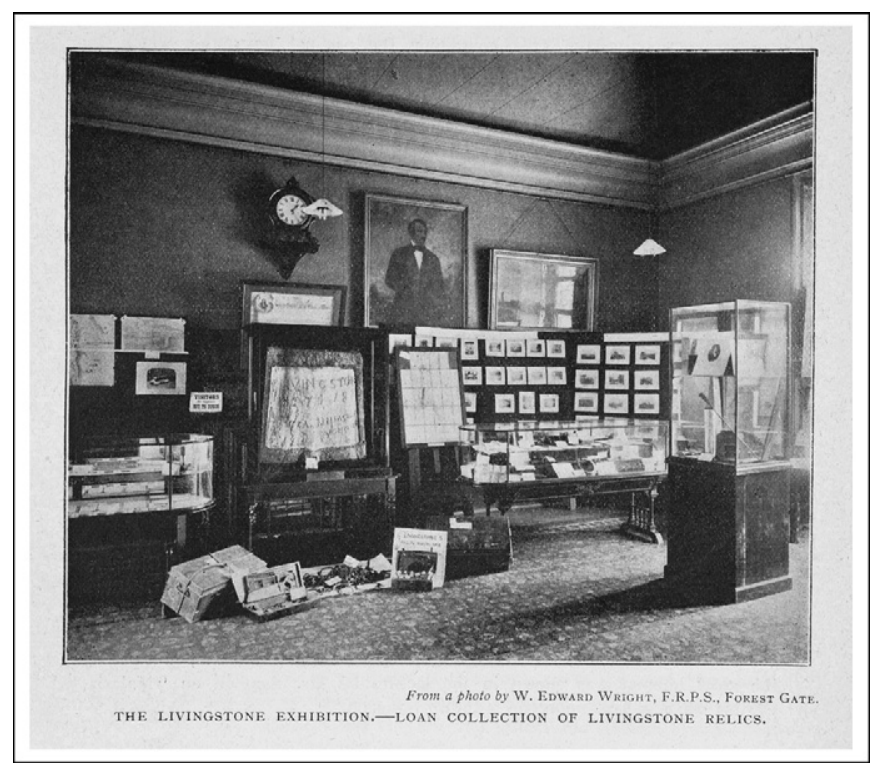

Figure 2. A display of David Livingstone's 'relics' at the Livingstone Exhibition. Reproduced from Climate 1(4), 1900, p. 136. Wellcome Library, London. had installed some of his products in a display of a model hospital erected by the Colonial Medical Service that showcased 'forms of medicine used in uncivilised and semi-civilised lands' [5]. Finally, pharmaceutical and medical firms also put in a strong appearance. There was Oppenheimer, Son and Co. marketing their patented 'Palatinoid' gelatin capsules, Howard and Sons with Howard's Quinine and other big players like Burroughs Wellcome \& Co., Allen and Hanbury, and Parke, Davis and Company.

In addition to their display at various exhibitions and trade fairs, the majority of the goods at the Livingstone Exhibition were also heavily advertised in medical and scientific publications. Such advertisements stress an important but often overlooked point: the practice of tropical medicine and hygiene was concerned with travelling to, and living in, tropical climates. In Britain, the production of knowledge about tropical disease might have taken place in medical schools in London and Liverpool [6], but the theatre for tropical medicine and hygiene was still the tropics. This might sound obvious, but it is easy to focus on the developing science of tropical medicine and overlook how difficult it was to put this science into practice; there are few examples of advances in tropical medicine that do not come bound up with a great clutter of outfit. And it is this associated paraphernalia that reveals most about how the British saw tropical people, places, health and hygiene. There are few better illustrations of this than 'Tabloid' brand medicine chests manufactured by Burroughs Wellcome \& Co. (BWC).

\section{'Tabloid' medicine chests}

Medicine chests were by no means novel commodities in late nineteenth and early twentieth century Britain but BWC's Tabloid brand improved upon larger and bulkier versions. They were known as Tabloid chests because of the compressed pills or 'tablets' they contained. Although this made them lighter and easier to haul, they housed similar patent medicines, dressings and basic surgical equipment to those found in earlier models. Nevertheless, BWC promoted their chests as cutting-edge medical equipment (Figure 3). With innovations like the Tabloid chest, BWC claimed to have 'contributed largely to the great advances of the times', arguing that they had 'not only kept pace with the latest developments in medicine and pharmacy' but also been 'pioneers in the introduction of the most notable agents employed in modern medicine' [7]. They marketed their Tabloid chests 'for military and naval purposes, for explorers, missionaries, travelling journalists, war correspondents, aeronauts, motorists, yachtsmen, planters'. In fact, they suggested, here was a piece of musthave equipment 'for the air, for the earth, for the depths, and for every clime under every condition' [8].

In spite of these grand claims, BWC showed an interest in the tropics, particularly after Secretary of State Joseph Chamberlain had 'taught the nation to think Imperially' to defend Britain's economic and political interests in tropical Africa [9]. The company reinforced the image of the tropics as deadly and disease ridden [10]: 'A danger far worse than that of broken limbs, of cuts and gun-shot wounds, hangs over the traveller in remote places, particularly in the 


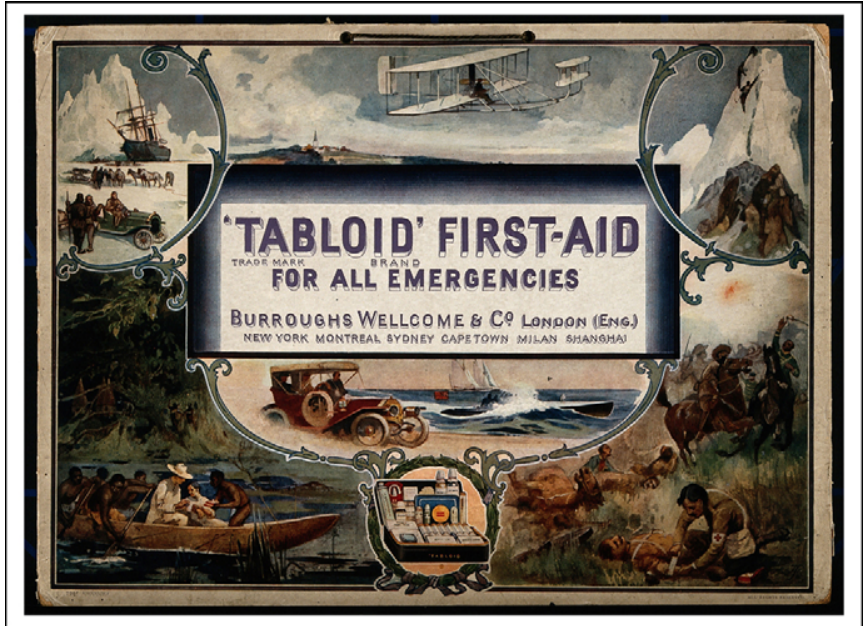

Figure 3. An advertisement for Burroughs Wellcome's Tabloid medicine chest showing various situations in which it could prove useful. Wellcome Library, London.

Tropics. The worst menace he has to face is disease', the company noted in one of its publications. The tropical colonies, they went on, 'are by far the most dangerous regions for travellers', where 'desolating ailments' are encountered, all of which 'are particularly fatal to the so-called white man who originates in temperate climates' [11]. BWC played on widespread fear of the diseased and deadly tropics to sell their chests, offering reassurance to middle-class white Europeans that the Tabloid chest would make them both safe and superior in Britain's tropical possessions. These chests, claimed BWC, went 'hand in hand with the advance of civilisation, the conquest against disease and the battle against ignorance and superstition' [12].
Often pictured alongside white Europeans, Tabloid medicine chests became standard equipment for scientists and medical practitioners in the tropics, embodying the achievements of western science and medicine and symbolising progress against the perceived ignorance and superstition of local people (Figure 4). In spite of this assumption of superiority of both white Europeans and western science, some of the modern tablets contained in the chest were composed of remedies hundreds, if not thousands of years old, often deriving from the very contexts they were supposedly helping the white European 'civilise'.

\section{Tropical clothing}

Another commodity that captures the Imperial view of tropical people, places, health and hygiene was tropical clothing. Various forms of tropical attire were on display at the Livingstone Exhibition of 1900, and their manufacturers, like BWC, also played on notions of white European superiority and fears of tropical climates, while simultaneously demonstrating the inherent instability of both British tropical medicine and white European identity in the tropical colonies.

In 1907, James Cantlie, co-founding editor of the Journal of Tropical Medicine, published an article addressing the importance of tropical clothing in relation to empire. He stated that 'The question of clothing in the tropics, both as regards colour and texture is of vital importance to the European dwelling in the tropics', and that 'it will be by suitable clothing that the modern man of the north will be enabled to conquer the exigencies of tropical life' [13]. Anticipating this emphasis on proper clothing, Burberry, Jaeger and several smaller firms occupied a great deal of space at the 1900 exhibition. Tropical attire was generally one of the first purchases before embarking on a long

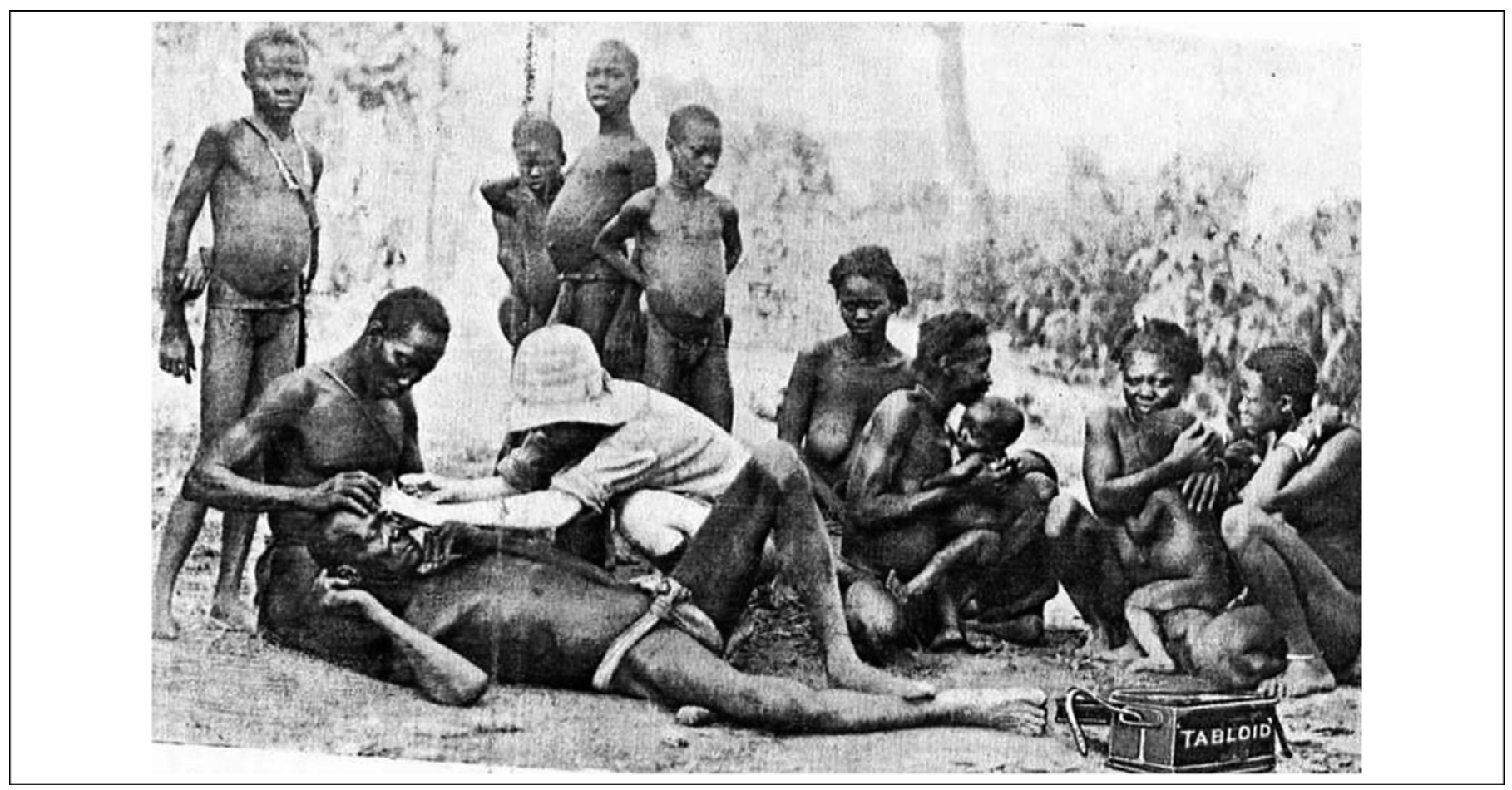

Figure 4. With a Tabloid brand medicine chest at her side (added to the photograph by BWC), Mrs. Glover (wife of Mr. T.A. Glover, leader of the 'Glover Expedition to Tibetsi') administers first aid to an African chief 'Mauled by a Leopard', reinforcing the impression of her 'civilising mission'. BWC, The Romance of Exploration, London, 1934 , p. 16. 
ocean-liner journey, and considered an important means of preserving health. 'When the journey is decided upon the question of outfit arises', travellers are 'besieged with advice as to the clothing required', wrote George Fink in the Journal of Tropical Medicine in 1909. 'The question of the clothing best suited to the white man in tropical regions is one of great importance as regards healthiness, comfort and efficiency' [14].

From the nineteenth century onwards, medical textbooks and manuals carried chapters on tropical clothing that focused on the best type of material to maintain equilibrium of physiological functions. Proper functioning of the skin was the 'grand and fundamental object in tropical prophylactics', suggested James Johnson in The Influence of Tropical Climates on European Constitutions [15]. Excessive perspiration or prevention of perspiration was believed to lead directly to problems of the stomach, liver and lungs. In addition, perspiration could lead to chilling effects if exposed to a cool breeze or sudden change of temperature, disrupting the function of internal organs and bringing on a direct or latent fever.

Well into the twentieth century and well after parasitology and microbiology had come to dominate discussions of tropical medicine, scientific and medical journals continued to publish complex theories of heat, dampness or chill altering physiological functions and precipitating disease. At the same time, they promoted flannel binders and other forms of tropical clothing to prevent such effects. The greatest support for climatic theories, however, appeared in manuals on tropical health and hygiene written for the general public. They often considered heat a great source of disease and debility for the tropical traveller, and after extensive sections on clothing many contained a significant portion of advertising.

Such advertisements helped maintain climatic fears, even when British scientific and medical circles were moving away from such ideas. By the early twentieth century, further developments in sanitation and parasitology cast greater doubt on theories of disease advocating a direct role for the climate. Metropolitan or colonial physicians who earnestly believed climate was a primary factor in disease were often subjects of ridicule. Nonetheless, climatic theories were reinforced when travellers - physicians and scientists included - purchased elaborate outfits explicitly designed to protect them from the tropical heat.

Historians have generally assumed clothing worn in the tropics served the purpose of maintaining strict separations between coloniser and colonised - identifying and legitimating the rule of a few over many. Elizabeth Collingham, for example, has argued that in India, the adoption of 'signifiers of Britishness and the medical occidentalization of the Anglo-Indian body' meant that 'a web of Britishness' became 'woven around the body' [16]. There can be little doubt that tropical attire set the British apart from the locals as Collingham suggests. But it did more than this. It also separated them from their own locality.

Tropical clothing was explicitly based on observations of local skin and practice, so it is possible to detect ongoing processes of hybridisation between white Europeans and local people woven into the fabric of these garments. This is not to say that sportsmen, explorers, missionaries, administrators and other British travellers believed they were 'going native' by wearing tropical clothing. Rather, they acknowledged the assumed biological inferiority of their bodies in tropical climates, but believed in their intellectual superiority by being able to manufacture protection given by nature. The primary goal of tropical attire was to prevent climatic disease, degeneration and reversion to a state of 'savagery', while at the same time conferring certain attributes of the 'savage'. Such a paradox played out on the body is a nice illustration of the complex relationship between coloniser and colonised.

Local people and practice continued to inform ideas of health and hygiene in significant ways, although these contributions were not necessarily obvious once they had been recast through western science and medicine. The cholera belt, or flannel binder, provides a good illustration of this. John Murray, in his manual How to Live in Tropical Africa, noted that 'The protection of the lower parts of the trunk is sadly overlooked by Europeans, who have much to learn in this matter from natives of hot countries...who wear gauze or other light material between the legs attached to or forming part of the kummerbund'. This, he went on 'should be a hint to Europeans, and teach them the necessity of protecting the genitals and rectum in hot countries' [17] (Figure 5).

The cholera belt was advocated after close observation of local practice, but the ultimate justification for its use derived from western science and medicine. Tropical attire

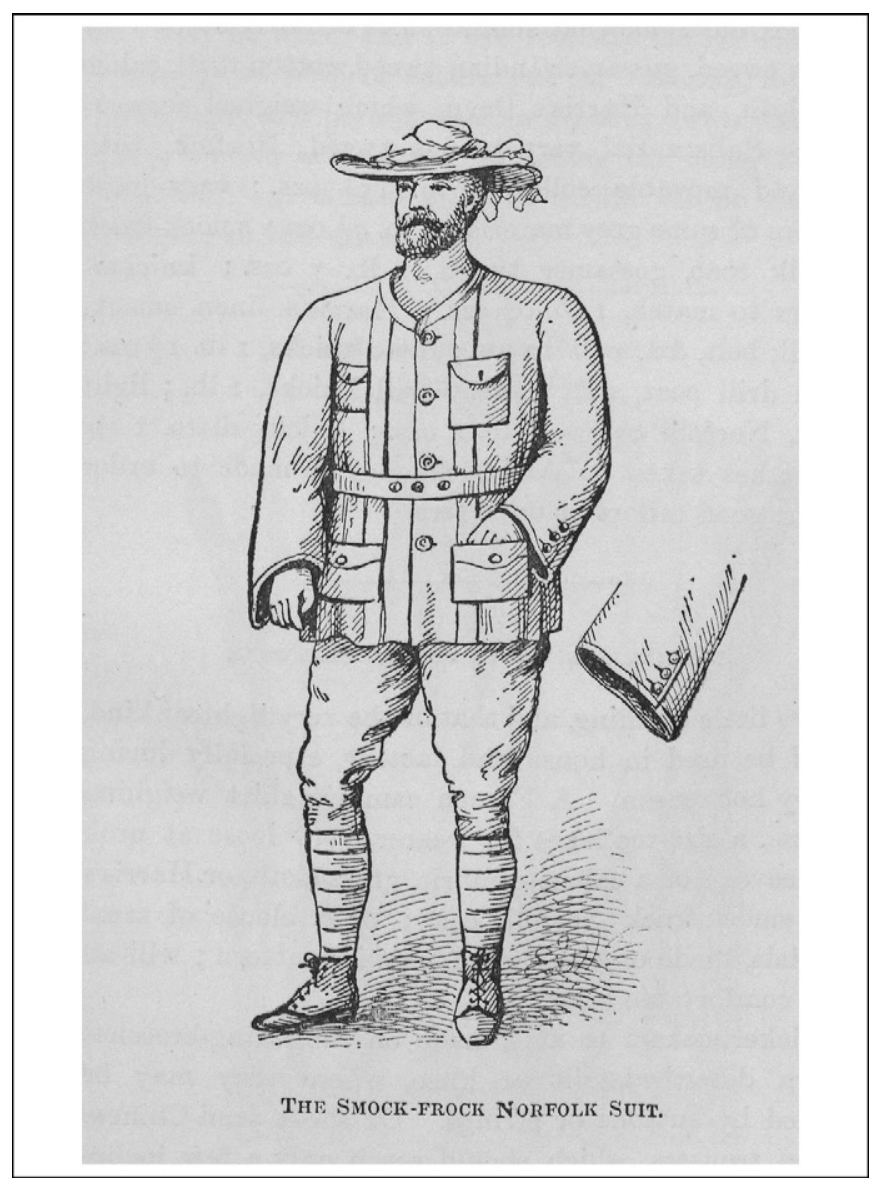

Figure 5. A linen smock-frock Norfolk suit as seen by John Murray in his manual on How to live in Tropical Africa, London, 1895. 
that was thought to resemble qualities of local skin was also justified in a similar manner. Nonetheless, wearing clothing believed to be imbued with qualities inherent to local peoples served as a reminder to white Europeans that they were no longer the same men and women that wore everyday clothing back home. As historian Christopher Breward has argued, in contrast to clothing worn by the city clerk in London, tropical attire provided 'glimpses of a colonial other-life' [18].

\section{Departure}

As tropical travellers set out from Britain at the start of the twentieth century, the assembly of a tropical outfit was an important endeavour that occupied the immediate attention of all travellers and their relatives. While most would have educated themselves on their specific destination, the abundance of advertisements and popular literature on tropical travel, buttressed by scientific, medical and state authority framed a picture of a generic tropical world with plenty of dangers to avoid. In this Imperial climate, it is easy to see how commodities like the Tabloid brand medicine chest and carefully tailored tropical clothing became must-have travel accessories. With their expectations and assumptions of the tropical world, those interested in the expansion of the British Empire readily bought into such products, setting out for the tropics with confidence they were protected against any malady they might encounter.

\section{References}

1 Battersby, C.H. (1900) The Livingstone Exhibition. Climate 1 (3), p. 96 2 Battersby, C.H. (1900) The Livingstone Exhibition. Climate 1 (2), p. 52 3 See Headrick, D. (1981) The Tools of Empire: Technology and European Imperialism in the Nineteenth Century, Oxford University Press (Oxford);

Adas, M. (1989) Machines as the Measure of Men: Science. Technology and Ideologies of Western Dominance, Cornell University Press (Ithaca);

Drayton, R.H. (2000) Nature's Government: Science. Imperial Britain and the 'Improvement' of the World, Yale University Press (New Haven)

4 Battersby, C.H. (1900) The Livingstone Exhibition. Climate 1 (2), p. 55 5 Battersby, C.H. (1900) The Livingstone Exhibition. Climate 1 (2), pp. $56-57$

6 See Worboys, M. (1976) The emergence of tropical medicine: a study in the establishment of a scientific specialty. In Perspectives on Western Medicine and the Experience of Scientific Disciplines (Lemaine, G., ed.), Warm Climates and Western Medicine. Amsterdam: Rodopi, pp. 181207; Wilkinson, L. and Hardy, A. (1998) The London School of Hygiene and Public Health: A Twentieth-Century Quest for Global Public Health. London: Keegan Paul International; Power, H. (1999) Tropical Medicine in the Twentieth Century: A History of the Liverpool School of Tropical Medicine, 1898-1990. London: Keegan Paul International

7 Burroughs Wellcome \& Co. (1912) The Application of Science to Industry: Souvenir of the Congress of the Universities of the Empire of London, Burroughs Wellcome \& Co. (London), p. 27

8 Burroughs Wellcome \& Co. (1912) The Application of Science to Industry: Souvenir of the Congress of the Universities of the Empire of London, Burroughs Wellcome \& Co. (London), p. 43
9 Burroughs Wellcome \& Co. (1912) The Application of Science to Industry: Souvenir of the Congress of the Universities of the Empire of London, Burroughs Wellcome \& Co. (London), p. 29;

For a discussion of British imperialism and colonialism in Africa see Robinson, R. and Gallagher, J. (1963) Africa and the Victorians: The Official Mind of Imperialism, Macmillan (London);

Wesseling, H.C. (1996) Divide and Rule: The Partition of Africa, 1880 1914, Praeger (London)

10 'Tabloid' brand medicine chests and their advertisements contributed to what David Arnold has described as a discourse of 'tropicality'. The 'Tropics' were understood as a specific geographical location extending from the equator to the North and South parallels of the tropic of Cancer and Capricorn, but, as Arnold suggests, they were also a conceptual space, something culturally and politically alien, as well as environmentally distinctive from the West. Throughout western discourse the tropics have been subject to a duality - a 'tropical alterity' - of paradisiacal and pestilential, the site of luxuriant abundance alongside primitiveness, violence and destruction. Language describing tropical climates was saturated with words such as paradise, plush and superabundant, alongside danger, disease and darkness. See Arnold, D. (1996) Inventing Topicality. In Arnold, D. (ed.), The Problem of Nature: Environment, Culture, and European Expansion, Blackwell (London), pp. 141-168; Arnold, D (2000) 'Illusory Riches': representations of the tropical world, 1840-1950. Singapore Journal of Tropical Geography 21, pp. 6-18. For a discussion of western 'visions' of tropical places and people as more of a negotiation between the west and the 'tropics', rather than a one-way Saidean construction by the west, see Driver, F. and Martins, L. (2005) Tropical Visions in an Age of Empire, University of Chicago Press (Chicago)

11 Burroughs Wellcome \& Co. (1934) The Romance of Exploration and Emergency First Aid from Stanley to Byrd, BWC (London), p. 8. There was intense debate over the ability of white Europeans to colonise and inhabit the tropical colonies permanently. Some believed it was simply a matter of hygiene and sanitation, while others believed it was impossible owing to inherent racial differences;

See Kennedy, D. (1990) The perils of the midday sun: climatic anxieties in the colonial tropics. In Imperialism and the Natural World (MacKenzie, J., ed.), Manchester: Manchester University Press, pp. 1- 35; Anderson, W. (1992) Climates of opinion: acclimatization in nineteenth-century France and England. Victorian Studies 35, pp. 135-137; Harrison, M. (1999) Climates and Constitutions: Health, Race, Environment and British Imperialism in India, 1600-1850. Oxford: Oxford University Press; Livingstone, D.N. (1999) Tropical climate and moral hygiene: the anatomy of a Victorian debate. British Journal for theHistory of Science 32, pp. 93-110

12 Burroughs Wellcome \& Co. (1934) The Romance of Exploration and Emergency First Aid from Stanley to Byrd, BWC (London), p. 29

13 Cantlie, J. (1907) Tropical clothing. Journal of Tropical Medicine (February), p. 71

14 Fink, G.H. (1909) Clothing in the tropics. Journal of Tropical Medicine (May), p. 136

15 Johnson, J. (1826) The Influence of Tropical Climates on European Constitutions, (3rd edn), Evert Duyckinck, George Long, Collins \& Co. (New York), p. 360

16 Collingham, E.M. (2001) Imperial Bodies: The Physical Experience of the Raj, c.1800-1947, Polity Press (Cambridge), p. 92

17 John, Murray (1895) How to Live in Tropical Africa, George Phillip \& Son (London), p. 287;

Johnson was one of the first Europeans to record the use of a cholera belt amongst local people, and suggest that white Europeans should do the same. See Johnson, J. (1826), Influence of Tropical Climates on European Constitutions, p. 391.

18 Breward, C. (1999) Sartorial spectacle: clothing and masculine identities in the imperial city, 1860-1914. In Imperial Cities (Driver, F. and Gilbert, D. (eds.), Imperial Cities. Manchester: Manchester University Press, p. 250 